\title{
Chronological changes in lung cancer surgery in a single Japanese institution
}

This article was published in the following Dove Press journal:

OncoTargets and Therapy

6 March 2017

Number of times this article has been viewed

\section{Haruhiko Nakamura \\ Hiroki Sakai \\ Hiroyuki Kimura \\ Tomoyuki Miyazawa \\ Hideki Marushima \\ Hisashi Saji}

Department of Chest Surgery, St Marianna University School of

Medicine, Kawasaki, Kanagawa, Japan
Correspondence: Haruhiko Nakamura Department of Chest Surgery, St Marianna University School of Medicine, 2-16-I Sugao, Miyamae-ku, Kawasaki, Kanagawa 2I6-85II, Japan Tel +8 I 449778 I I I ext 3230 Fax +8I 449765792 Email h-nakamura@marianna-u.ac.jp
Background: The aim of this study was to evaluate the chronological changes in epidemiological factors and surgical outcomes in patients with lung cancer who underwent surgery in a single Japanese institution.

Patients and methods: A clinicopathological database of patients with lung cancer who underwent surgery with curative intent from January 1974 to December 2014 was reviewed. The chronological changes in various factors, including patient's age, sex, histological type, tumor size, pathological stage ( $\mathrm{p}$-stage), surgical method, operative time, intraoperative blood loss, 30-day mortality, and postoperative overall survival (OS), were evaluated.

Results: A total of 1,616 patients were included. The numbers of resected patients, females, adenocarcinomas, p-stage IA patients, and age at the time of surgery increased with time, but tumor size decreased (all $P<0.0001$ ). Concerning surgical methods, the number of sublobar resections increased, but that of pneumonectomies decreased $(P<0.0001)$. The mean operative time, intraoperative blood loss, and the postoperative 30-day mortality rate decreased (all $P<0.0001)$. When the patients were divided into two groups (1974-2004 and 2005-2014), the 5-year OS rates for all patients and for p-stage IA patients improved from $44 \%$ to $79 \%$ and from $73 \%$ to $89 \%$, respectively (all $P<0.0001$ ). The best 5 -year OS rate was obtained for sublobar resection $(73 \%)$, followed by lobectomy $(60 \%)$, combined resection $(22 \%)$, and pneumonectomy $(21 \% ; P<0.0001)$.

Conclusion: Changes in epidemiological factors, a trend toward less invasive surgery, and a remarkably improved postoperative OS were confirmed, which demonstrated the increasingly important role of surgery in therapeutic strategies for lung cancer.

Keywords: lung cancer, surgery, sublobar resection, less invasive surgery, 30-day mortality

\section{Introduction}

Lung cancer is one of the leading causes of cancer-related deaths in most developed countries, including Japan where 73,000 people died from lung cancer in 2013. Although age-adjusted lung cancer mortality has plateaued because of decreased tobacco consumption in Japan, the actual number of patients who died from lung cancer has been rapidly increasing with the aging of the population. Recently, a variety of new molecular targeted anticancer drugs or computer-controlled stereotactic radiotherapeutic methods have been introduced to treat lung cancer, but surgery is still the main therapy to cure locoregionally confined lung cancer.

The St Marianna University School of Medicine was established in 1971 as a private medical school hospital in Kawasaki city, which was a bedroom community near Tokyo. The first lung cancer surgery was recorded in 1974, and only a small number of patients had undergone lung resection by the end of 1984 . However, since then, lung resections have increasingly been performed. Recently, $\sim 120$ patients with 
lung cancer per year have been operated on by six staff of thoracic surgeons in our department. Because long chronological changes in epidemiology and surgical outcomes for lung cancer in a single institution have rarely been reported, we retrospectively analyzed patients with lung cancer who underwent surgery in our department over the past 41 years. We believe that our findings demonstrate a representative trend in lung cancer surgery performed in a high-volume hospital in Japan. ${ }^{1}$

\section{Patients and methods}

\section{Patients}

This retrospective study was approved by the Institutional Review Board of the St Marianna University School of Medicine (No 2233, November 6, 2015). Written informed consent was waived by the review board, because this was a retrospective study in which patients treated in different segments of a 41-year period were analyzed. A clinicopathological database of patients with lung cancer who underwent surgery with curative intent in our department from January 1974 to December 2014 was reviewed to obtain the records of patients. The total period was divided into the following seven segments: 1974-1984, 1985-1989, 19901994, 1995-1999, 2000-2004, 2005-2009, and 2010-2014. Surgical methods were classified into four types as follows: sublobar resection (wedge resection or segmentectomy), lobectomy (including bilobectomy), pneumonectomy, and combined lung resection with adjacent organs. Bronchial or tracheal resections without lung resection were excluded. Postoperative pathological stages ( $\mathrm{p}$-stages) were determined according to the most recent international staging criteria for lung cancer, published by the American Joint Committee on Cancer/Union for International Cancer Control/International Association for the Study of Lung Cancer in 2009. ${ }^{2}$

\section{Statistical analysis}

Categorical variables for contingency tables were tested using the chi-square test. Continuous variables in multiple groups were tested using the Kruskal-Wallis test. The estimated survival rate after surgery was calculated using the Kaplan-Meier method, and survival differences between patient groups were tested using the log-rank test. $P<0.05$ was considered to indicate a significant difference.

\section{Results}

\section{Clinicopathological factors}

A total of 1,616 patients, 1,054 males and 562 females with a mean age of $66 \pm 10$ years (range, 13-90 years), were included.
The mean postoperative follow-up period was $44 \pm 36$ months (range, 1-329 months). The chronological changes in various clinicopathological factors in the resected patients with lung cancer are shown in Table 1 . The numbers of resected patients in each divided period gradually increased during the study period. When the data in the first period (1974-1984) and the last period (2010-2014) were compared, the mean tumor size decreased (49-24 mm, $P<0.0001$ ) and the following factors significantly increased: the mean age of patients at the time of surgery (61-69 years), female patients $(27 \%-42 \%)$, adenocarcinoma $(54 \%-74 \%)$, tumors $\leq 20 \mathrm{~mm}(12 \%-50 \%)$, patients in p-stage IA $(16 \%-55 \%$, all $P<0.0001)$.

\section{Surgical methods and outcomes}

The chronological changes in the surgical methods and outcomes are shown in Table 2. During the 41 years, sublobar resections increased $(3 \%-38 \%)$, but pneumonectomies decreased $(16 \%-4 \%, P<0.0001)$. The postoperative 30 -day mortality rate decreased $(1.5 \%-0.2 \%, P=0.0071)$. The mean operative time and intraoperative blood loss (IBL) decreased for all surgeries (326-171 $\mathrm{min}, 874-121 \mathrm{~mL}$ ) and specifically for lobectomies (322-201 min, 837-149 mL; $P<0.0001)$.

When all patients were divided into two groups (1974-2004, $\mathrm{n}=868$ and 2005-2014, n=748), the 5-year overall survival (OS) rates of the groups were $44.1 \%$ and $78.5 \%$, respectively $(P<0.0001$; Figure 1$)$. When limited to the patients in p-stage IA, a significant difference in OS was found again between the two groups; the 5-year OS rates were $72.7 \%$ and $88.9 \%$, respectively ( $P<0.0001$; Figure 2$)$.

Regarding the associations between the surgical methods, which were selected on the basis of the tumor extent, the best 5-year OS was obtained for patients who underwent sublobar resection (73.1\%), followed by lobectomy $(60.2 \%)$, combined resection (22.3\%), and pneumonectomy $(20.6 \%$, $P<0.0001$; Figure 3).

\section{Discussion}

This study showed that lung cancer epidemiology and surgical outcomes have changed remarkably during the past 41 years. Of the epidemiological factors, the proportions of adenocarcinoma, female sex, early stage, and older patients increased significantly, and we speculated that these changes were closely associated with surgical outcomes.

Although a trend toward increasing prevalence of adenocarcinoma has been observed worldwide, ${ }^{3-5}$ the exact reasons for this phenomenon are unclear. ${ }^{6}$ One plausible reason is the influence of recent tobacco filters that selectively allow carcinogenic microparticles to be inspired into the 
Table I Chronological changes in various clinicopathological factors in the resected patients with lung cancer

\begin{tabular}{|c|c|c|c|c|c|c|c|c|}
\hline Period & $1974-1984$ & $1985-1989$ & $1990-1994$ & $1995-1999$ & 2000-2004 & 2005-2009 & $2010-2014$ & $P$-value \\
\hline Patient number & 68 & 133 & 180 & 263 & 224 & 261 & 487 & \\
\hline Age (years)* & $61 \pm 11$ & $64 \pm 10$ & $63 \pm 12$ & $66 \pm 10$ & $67 \pm 10$ & $68 \pm 10$ & $69 \pm 9$ & $<0.000 I^{a}$ \\
\hline Female (\%) & $18(26.5)$ & $23(17.3)$ & $60(33.3)$ & $80(30.4)$ & $78(34.8)$ & $106(40.6)$ & $197(40.5)$ & $<0.000 \mathrm{I}^{\mathrm{a}}$ \\
\hline \multicolumn{9}{|l|}{ Histological type } \\
\hline $\mathrm{AD}(\%)$ & $37(54.4)$ & $50(37.6)$ & $10 \mid(56.1)$ & $158(60.1)$ & $140(62.5)$ & $177(67.8)$ & $360(73.9)$ & \\
\hline SQ (\%) & $21(30.1)$ & $62(46.6)$ & $59(32.8)$ & $85(32.3)$ & $6 I(27.2)$ & $37(14.2)$ & $85(17.5)$ & \\
\hline LA & 5 & 7 & 5 & 6 & 7 & 12 & 19 & \\
\hline ADSQ & 1 & 4 & 7 & 7 & 8 & 19 & 9 & \\
\hline SM & 3 & 7 & 5 & I & 3 & 8 & 4 & \\
\hline $\mathrm{CA}$ & I & I & 2 & I & 4 & 2 & 5 & \\
\hline Others & 0 & 2 & I & 5 & I & 6 & 5 & $<0.000 \mathrm{I}^{\mathrm{b}}$ \\
\hline Tumor size $(\mathrm{mm})^{*}$ & $49 \pm 36$ & $42 \pm 25$ & $4 I \pm 28$ & $40 \pm 24$ & $33 \pm 22$ & $29 \pm 19$ & $24 \pm 14$ & $<0.000 \mathrm{I}^{\mathrm{a}}$ \\
\hline Tumor size $\leq 20 \mathrm{~mm}(\%)$ & $8(11.8)$ & $27(20.3)$ & $50(27.8)$ & $60(22.8)$ & $74(33.0)$ & $107(4 \mid .0)$ & $245(50.3)$ & $<0.000 \mathrm{I}^{\mathrm{a}}$ \\
\hline \multicolumn{9}{|l|}{ P-stage** } \\
\hline pIA (\%) & II (I6.2) & $25(19.1)$ & $44(25.1)$ & $58(22.3)$ & I0I (45.3) & $116(46.4)$ & $202(55.3)$ & \\
\hline pIB & 15 & 33 & 36 & 60 & 40 & 54 & 76 & \\
\hline PllA & 16 & 25 & 23 & 33 & 14 & 21 & 18 & \\
\hline pllB & 8 & 25 & 13 & 30 & 13 & 22 & 20 & \\
\hline PIIIA & 15 & 32 & 40 & 72 & 37 & 36 & 43 & \\
\hline pIIIB & 0 & 4 & 3 & I & 9 & 0 & 0 & \\
\hline pIV & 3 & 7 & 16 & 6 & 9 & I & 5 & $<0.000 I^{b}$ \\
\hline
\end{tabular}

Notes: *Mean \pm SD; ${ }^{* *} 86$ cases were excluded since information about pathological lymph node metastasis was not available due to limited resection. ${ }^{\mathrm{K}} \mathrm{Kruskal}-\mathrm{Wallis}$ test; ${ }^{\text {b}}$ chi-square test.

Abbreviations: AD, adenocarcinoma; SQ, squamous cell carcinoma; LA, large cell carcinoma; ADSQ, adenosquamous carcinoma; SM, small cell carcinoma; CA, carcinoid; P-stage, pathological stage.

lung periphery where adenocarcinomas develop. However, we cannot explain the increase in lung adenocarcinomas in Japanese or East Asian female patients for this reason because most of these patients do not smoke. ${ }^{7}$ Because the number of Japanese male smokers has been decreasing, the influence of environmental tobacco smoke suggested in some Western countries ${ }^{8}$ may be limited. Exposure to cooking oils may be an important factor in causing lung cancer in nonsmoking Chinese females, ${ }^{9}$ but this is not applicable to Japanese females.

In the most recent nationwide surveillance for postsurgical outcomes in lung cancer by the Japanese Joint Committee for Lung Cancer Registration, the postoperative 5-year OS rate in 11,663 patients who underwent surgery in 2004 was $69.6 \% .^{10}$ In previous surveillance reports, the survival rate was $51.9 \%$ in 1994 and $61.6 \%$ in 1999 , which indicated

Table 2 Chronological changes in surgery for lung cancer

\begin{tabular}{|c|c|c|c|c|c|c|c|c|}
\hline Period & $1974-1984$ & | 985-1989 & $1990-1994$ & $1995-1999$ & 2000-2004 & 2005-2009 & $2010-2014$ & $P$-value \\
\hline \multicolumn{9}{|l|}{ Surgical method } \\
\hline Sublobar resection (\%) & $2(2.9)$ & $3(2.3)$ & $10(5.6)$ & $8(3.0)$ & $14(6.3)$ & $28(10.7)$ & $185(38.0)$ & \\
\hline Lobectomy & 55 & 93 & 129 & 214 & 195 & 226 & 281 & \\
\hline Pneumonectomy (\%) & II (I6.2) & $25(18.8)$ & $33(18.3)$ & $24(9.1)$ & $15(6.7)$ & $5(1.9)$ & $18(3.7)$ & \\
\hline Combined resection & $0(0.0)$ & $12(9.0)$ & $8(4.4)$ & $17(6.5)$ & $0(0.0)$ & $2(0.8 \%)$ & $3(0.6 \%)$ & $<0.000 I^{a}$ \\
\hline 30-day mortality (\%) & $\mathrm{I}(1.5)$ & $6(4.5)$ & $4(2.2)$ & $5(1.9)$ & $3(1.3)$ & $0(0.0)$ & $\mathrm{I}(0.2)$ & $0.007 I^{\mathrm{a}}$ \\
\hline \multicolumn{9}{|l|}{ All surgery, $n=1,616$} \\
\hline OT $(\min )^{*}$ & $326 \pm 79$ & $318 \pm 96$ & $267 \pm 94$ & $284 \pm 92$ & $268 \pm 76$ & $249 \pm 84$ & $|7| \pm 72$ & $<0.000 \mathrm{I}^{\mathrm{b}}$ \\
\hline $\mathrm{IBL}(\mathrm{mL})^{*}$ & $874 \pm 558$ & $867 \pm 782$ & $717 \pm 615$ & $588 \pm 5 \mid 4$ & $453 \pm 457$ & $307 \pm 376$ & $|2| \pm 204$ & $<0.000 \mathrm{I}^{\mathrm{b}}$ \\
\hline 5-year OS (\%) & 46.7 & 34.8 & 28.8 & 45.4 & 55.4 & 74.9 & 86.0 & $<0.000 \mathrm{I}^{\mathrm{c}}$ \\
\hline \multicolumn{9}{|l|}{ Lobectomy, n=I, 196} \\
\hline OT $(\min )^{*}$ & $322 \pm 76$ & $304 \pm 85$ & $262 \pm 78$ & $28 I \pm 91$ & $275 \pm 68$ & $258 \pm 69$ & $201 \pm 59$ & $<0.000 \mathrm{I}^{\mathrm{b}}$ \\
\hline $\mathrm{IBL}(\mathrm{mL})^{*}$ & $837 \pm 545$ & $699 \pm 470$ & $645 \pm 508$ & $563 \pm 535$ & $452 \pm 455$ & $312 \pm 365$ & $149 \pm 166$ & $<0.000 \mathrm{I}^{\mathrm{b}}$ \\
\hline 5-year OS (\%) & 52.2 & 41.9 & 33.8 & 53.4 & 59.1 & 73.5 & 87.8 & $<0.0001^{c}$ \\
\hline
\end{tabular}

Notes: *Mean $\pm \mathrm{SD}$; ${ }^{\mathrm{C}}$ chi-square test; ${ }^{\mathrm{b}}$ Kruskal-Wallis test; ${ }^{\mathrm{c} l o g-r a n k}$ test.

Abbreviations: OT, operative time; IBL, intraoperative blood loss; OS, overall survival. 


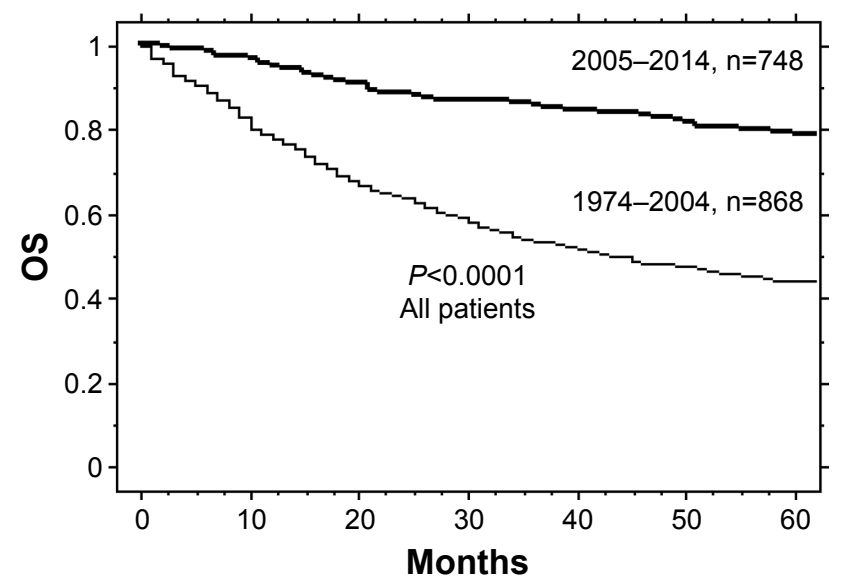

Figure I OS curves of all patients who underwent resection for lung cancer show a significant survival difference between patients from 1974 to $2004(n=868)$ and those from 2005 to 2014 ( $n=748$; log-rank test, $P<0.000$ I).

Abbreviation: OS, overall survival.

gradual improvement every 5 years. ${ }^{11,12}$ The postoperative 30-day mortality rates also have been decreasing and were $1.4 \%$ in $1994,0.9 \%$ in 1999 , and $0.4 \%$ in $2004 .{ }^{10}$ Similar periodical improvement in the OS and 30-day mortality rates was found in the current study, which indicates that our institutional results are similar to those for the typical Japanese standard level of lung cancer surgery. Because our data are based on the experience of a single institution, the potential for selection bias in our results should be taken into consideration when applying the findings to a larger population. Prospective multi-institutional studies in selected representative sites in a region are ideal for minimizing bias.

Internationally, 30-day mortality rates reported from other countries are higher than those in Japan and were

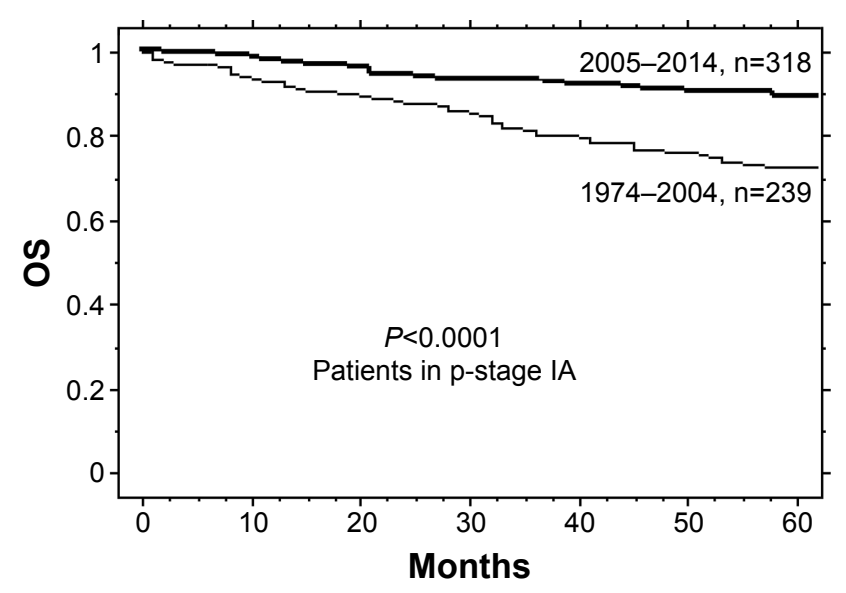

Figure 2 OS curves of $\mathrm{p}$-stage IA patients who underwent resection for lung cancer show a significant survival difference between patients from 1974 to $2004(n=239)$ and those from 2005 to 2014 ( $n=3 \mid 8$; log-rank test, $P<0.000$ I).

Abbreviations: OS, overall survival; $p$-stage, pathological stage.

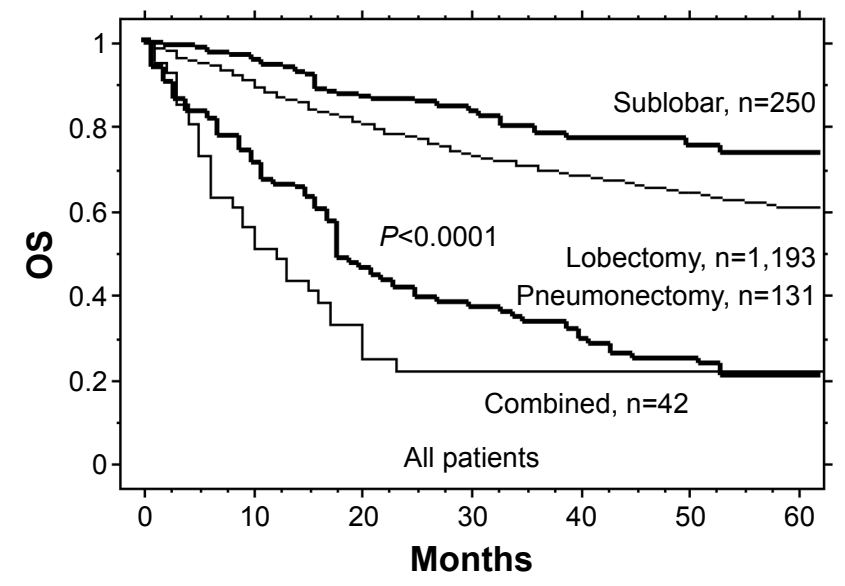

Figure 3 OS curves of patients are significantly different among four surgical methods including sublobar resection (wedge resection or segmentectomy), lobectomy (including bilobectomy), pneumonectomy, and combined resection with adjacent organs (log-rank test, $P<0.000 \mathrm{I}$ ).

Abbreviation: OS, overall survival.

3.4\% (2004-2009) in North America, ${ }^{13} 3.0 \%$ in England (2004-2010), ${ }^{14} 2.1 \%$ in Denmark (2007-2011), ${ }^{15}$ and 3.0\% in Norway (2006-2007). ${ }^{16}$ The Japanese Board of General Thoracic Surgery has certified 1,300 general thoracic surgeons (GTSs) since 2005, and the number of GTSs was reported to be associated with lower 30-day mortality rates in Japanese hospitals. ${ }^{17}$ Because there have been usually three to six certified GTSs in our department, this certification system appears to be working with respect to the safety and efficacy of lung cancer surgery.

Drastic improvement in postsurgical OS can be explained by multiple factors. First, the frequency of early-stage detection of lung cancer has increased with the increasing use of chest computed tomographic scanners in Japan, which has led to an increasing proportion of patients diagnosed as having p-stage IA disease. ${ }^{18}$ Organ-sparing sublobar resection can be a curative operation for these early-stage tumors. ${ }^{19}$ Second, the number of nonsmoking female patients has increased. The OS in female patients is known to be significantly better than that in male patients either after complete resection or nonsurgical treatment in any disease stages. ${ }^{20,21}$ Third, continuous progress in less invasive lung cancer surgery, including advanced techniques of videoassisted thoracoscopic surgery (VATS), has resulted in shortened operation time and decreased IBL. VATS was introduced for use in lung cancer surgery in our department in 2005. We previously reported the close association between a lower amount of IBL and better postsurgical OS in lung cancer, ${ }^{22}$ which suggests that recent less invasive surgery may improve long-term survival. Accelerated aging of the Japanese population is the main cause of the remarkable 
increase in older patients with lung cancer, which was also observed in the current study. Because older patients often have comorbidities, such as cardiopulmonary dysfunction, organ-sparing sublobar resection is useful for these patients to lower postsurgical morbidity and mortality. Fourth, progress in anesthesia and pre- and postsurgical care should contribute to decreased perioperative mortality and morbidity. Finally, advances in nonsurgical therapy for lung cancer, such as molecular targeted therapy, chemotherapy, and radiotherapy, may prolong survival of relapsed patients. ${ }^{23}$ Lung adenocarcinomas developed in Asian nonsmoking patients frequently carry epidermal growth factor receptor (EGFR) mutations that can be targeted by EGFR tyrosine kinase inhibitors. Recent molecular targeted therapy and advanced chemotherapy might contribute to improved OS in relapsed patients, particularly for those treated during the last 10 years. All these factors might have contributed to the finding of improved postsurgical OS shown in the current study.

\section{Conclusion}

The chronological changes in epidemiological factors and a trend toward less invasive surgery were confirmed in the treatment of resected lung cancers in our institution during the 41-year study period. In particular, the improvement in postsurgical OS during the period was remarkable. Thoracic surgeons should monitor changes in the status of patients with lung cancer and adjust the surgical strategies so that the best outcomes can be achieved.

\section{Acknowledgment}

This study did not receive any specific grant from funding agencies in the public, commercial, or not-for-profit sectors.

\section{Disclosure}

The authors report no conflicts of interest in this work.

\section{References}

1. Otake H, Yasunaga H, Horiguchi H, Matsutani N, Matsuda S, Ohe K. Impact of hospital volume on chest tube duration, length of stay, and mortality after lobectomy. Ann Thorac Surg. 2011;92(3):1069-1074.

2. Vallieres E, Shepherd FA, Crowley J, et al; International Association for the Study of Lung Cancer International Staging Committee and Participating Institutions. The IASLC Lung Cancer Staging Project: proposals regarding the relevance of TNM in the pathologic staging of small cell lung cancer in the forthcoming (seventh) edition of the TNM classification for lung cancer. $J$ Thorac Oncol. 2009;4(9): 1049-1059.

3. Au JS, Mang OW, Foo W, Law SC. Time trends of lung cancer incidence by histologic types and smoking prevalence in Hong Kong 1983-2000. Lung Cancer. 2004;45(2):143-152.
4. Sisti J, Boffetta P. What proportion of lung cancer in never-smokers can be attributed to known risk factors? Int J Cancer. 2012; 131(2):265-275.

5. Nakamura H, Saji H. Worldwide trend of increasing primary adenocarcinoma of the lung. Surg Today. 2014;44(6):1004-1012.

6. Samet JM, Avila-Tang E, Boffetta P, et al. Lung cancer in never smokers: clinical epidemiology and environmental risk factors. Clin Cancer Res. 2009;15(18):5626-5645.

7. Epplein M, Schwartz SM, Potter JD, Weiss NS. Smoking-adjusted lung cancer incidence among Asian-Americans (United States). Cancer Causes Control. 2005;16(9):1085-1090.

8. Fontham ET, Correa P, Reynolds P, et al. Environmental tobacco smoke and lung cancer in nonsmoking women - a multicenter study. JAMA. 1994;271:1752-1759.

9. Ko YC, Lee CH, Chen MJ, et al. Risk factors for primary lung cancer among non-smoking women in Taiwan. Int J Epidemiol. 1997;26(1): 24-31.

10. Sawabata N, Miyaoka E, Asamura H, et al; Japanese Joint Committee for Lung Cancer Registration. Japanese lung cancer registry study of 11,663 surgical cases in 2004: demographic and prognosis changes over decade. J Thorac Oncol. 2011;6(7):1229-1235.

11. Goya T, Asamura H, Yoshimura H, et al; Japanese Joint Committee of Lung Cancer Registry. Prognosis of 6644 resected non-small cell lung cancers in Japan: a Japanese lung cancer registry study. Lung Cancer. 2005;50(2):227-234.

12. Asamura H, Goya T, Koshiishi Y, et al; Japanese Joint Committee of Lung Cancer Registry. A Japanese Lung Cancer Registry study: prognosis of 13,010 resected lung cancers. J Thorac Oncol. 2008;3(1): $46-52$.

13. Rosen JE, Hancock JG, Kim AW, Detterbeck FC, Boffa DJ. Predictors of mortality after surgical management of lung cancer in the National Cancer Database. Ann Thorac Surg. 2014;98(6):1953-1960.

14. Powell HA, Tata LJ, Baldwin DR, Stanley RA, Khakwani A, Hubbard RB. Early mortality after surgical resection for lung cancer: an analysis of the English national lung cancer audit. Thorax. 2013;68(9):826-834.

15. Green A, Hauge J, Iachina M, Jakobsen E. The mortality after surgery in primary lung cancer: results from the Danish Lung Cancer Registry. Eur J Cardiothorac Surg. 2016;49(2):589-594.

16. Strand TE, Bartnes K, Rostad H. National trends in lung cancer surgery. Eur J Cardiothorac Surg. 2012;42:355-358.

17. Nagayasu T, Sato S, Yamamoto H, et al. The impact of certification of general thoracic surgeons on lung cancer mortality: a survey by The Japanese Association for Thoracic Surgery. Eur J Cardiothorac Surg. 2016;49(5):e134-e140.

18. Kondo R, Yoshida K, Kawakami S, et al. Efficacy of CT screening for lung cancer in never-smokers: analysis of Japanese cases detected using a low-dose CT screen. Lung Cancer. 2011;74(3):426-432.

19. Nakamura H, Saji H, Marushima H, Tagaya R, Kimura H, Takagi M. Glucose uptake values in positron emission tomography are useful to predict survival after sublobar resection for lung cancer. Thorac Cardiovasc Surg. Epub Feb 24, 2016.

20. Sakurai H, Asamura H, Goya T, et al; Japanese Joint Committee for Lung Cancer Registration. Survival differences by gender for resected non-small cell lung cancer: a retrospective analysis of 12,509 cases in a Japanese Lung Cancer Registry study. J Thorac Oncol. 2010;5(10):1594-1601.

21. Nakamura H, Ando K, Shinmyo T, et al. Female gender is an independent prognostic factor in non-small-cell lung cancer: a meta-analysis. Ann Thorac Cardiovasc Surg. 2011;17(5):469-480.

22. Nakamura H, Saji H, Kurimoto N, Shinmyo T, Tagaya R. Impact of intraoperative blood loss on long-term survival after lung cancer resection. Ann Thorac Cardiovasc Surg. 2015;21(1):18-23.

23. Janjigian YY, Park BJ, Zakowski MF, et al. Impact on disease-free survival of adjuvant erlotinib or gefitinib in patients with resected lung adenocarcinomas that harbor EGFR mutations. J Thorac Oncol. 2011;6(3):569-575. 


\section{Publish your work in this journal}

OncoTargets and Therapy is an international, peer-reviewed, open access journal focusing on the pathological basis of all cancers, potential targets for therapy and treatment protocols employed to improve the management of cancer patients. The journal also focuses on the impact of management programs and new therapeutic agents and protocols on

patient perspectives such as quality of life, adherence and satisfaction. The manuscript management system is completely online and includes a very quick and fair peer-review system, which is all easy to use. Visit http://www.dovepress.com/testimonials.php to read real quotes from published authors.

Submit your manuscript here: http://www.dovepress.com/oncotargets-and-therapy-journal 